\title{
Über die Darstellung von reinem Natriumhydroxyd für den Laboratoriumsgebrauch.
}

\author{
Von \\ F. W. Küsteli.
}

Das käufliche Natriumhydroxyd ist für viele Zwecke zu unrein, sowohl bei präparativen, wie namentlich bei analytischen Arbeiten macht sich der nie fehlende Gehalt an Karbonat, an Aluminiumhydroxyd und anderen Verunreinigungen störend bemerkbar. Namentlich in der Acidimetrie ist der Kohlensäuregehalt sehr unangenehm, indem der Farbumschlag der Indikatoren durch die Gegenwart des Karbonats ganz aufserordentlich an Schärfe einbül'st. Fachgenossen, die, wie die grofse Mehrzahl, bisher immer nur mit käuflichem Natrium- resp. Kaliumbydroxyd gearbeitet baben, werden beim Arbeiten mit wirklich reinem Natriumbydroxyd überrascht sein über die Exaktheit des Farbumschlages bei der Titration. ${ }^{1}$

Bedarf man nur kleinerer Mengen von ganz reinem Natriumhydroxyd, so kann man dasselbe leicht dadurch herstellen, dafs man metallisches Natrium - am besten als Draht oder Band - in einer Platin- oder Silberschale in einem abgeschlossenen Raum, z. B. in einem Exsikkator über Wasser zertielsen lälst. ${ }^{2}$ Jedoch geht das ziemlich langsam, da das Metall bald von der höchst konzentrierten. Lauge bedeckt wird und dann nur sehr träge reagiert. Vor dem direkten Behandeln irgend grölserer Mengen Natrium mit Wasser in der einen oder anderen Weise mufs aber dringend gewarnt werden, denn es ist bekannt, dafs hierbei nur zu leicht auch bei Verwendung blanker Natriumbarren furchtbare Explosionen erfolgen, deren Wesen noch nicht aufgeklärt ist, die aber vielleicht auf das Vorhandensein von

1 Vergl. hierzu F. W. Küster u. Max Grüters, Z. anorg. Chem. \$5, $454 \mathrm{ff}$.

2 Vergl. W. Ostwaxn, "Grundlinien“, S. 484; Ostwald-Lutuen, „Physikocbemische Messungen", s. $424 \mathrm{ff}$. 
Natriumkarbiden zurückzuführen sind. In meinem Laboratorium sind in früheren Jahren trotz grölster Vorsicht kurz hintereinander zwei derartige Explosionen erfolgt, die leicht Menschenleben hätten kosten können.

Aus Natrium hergestelltes Natriumhydroxyd ist nun $z$ war im Handel zu haben, wenn auch zu einem sehr hohen Preise. Als ich aber vor einigen Jahren für einen bestimmten Zweck grölsere Mengen reinen Natriumhydroxyds bedurfte, liefs ich mir dies käufliche Produkt aus mehreren renommierten Fabriken kommen, fand jedoch, dals es im Durchschnitt nicht viel weniger, ja in einem Falle sogar mehr Karbonat enthielt, als das käufliche mit Alkohol gereinigte Präparat. Ich stellte deshalb eine Vorrichtung zusammen, die ohne nennenswerten Arbeitsaufwand kontinuierlich und selbsttätig ein absolut reines Natriumbydroxyd aus Natrium zu sehr billigem Preise und in solchen Mengen liefert, dafs dadurch der laufende Bedarf eines grölseren Laboratoriums gedeckt werden kann.

Eine recht grofse Schale mit flachem Boden (Kristallisierschale) aus Glas, Porzellan oder glasiertem Ton (Durchmesser z. B. $50 \mathrm{~cm}$ ) fült man einige Zentimeter hoch mit Wasser. In die Mlitte kommt eine niedrige, weithalsige Flasche (Tiegel oder Schale) aus Platin, Silber oder Nickel ${ }^{1}$ von 500-1000 ccm Inhalt, darüber ein recht grolser, unten geschlossener Trichter, der aus dem käutlichen Nickeldrahtgewebe gebogen wird. Den Trichter trägt ein Dreifuls so, dals seine Spitze sich einige Zentimeter über der Flaschenöffnung befindet.

In den Drahtnetztrichter wird eine gröfsere Zahl von Natriumbarren gelegt (mehrere Hundert Gramm), von denen die Kruste heruntergeschnitten ist. Über Trichter und Flasche wird dann eine grolse Glasglocke gestürzt, die einen nur wenig kleineren Durchmesser hat, als die Schale. Damit die Glocke nicht fest auf dem Boden der Schale aufsteht, werden einige Glasstäbe untergelegt. D)as Wasser schliel'st dann der Raum in der Glocke nach aufsen hin ab.

Das Natrium beginnt nun sofort zu zerfliefsen, was man daran merkt, dafs Wasserstoff in gleichmälsigen grofsen Blasen durch das Wasser entweicht. Das entstandene Natriumhydroxyd tropft als sehr konzentrierte, öldicke Lösung in die Flasche. Da so die Oberfläche des Natriums immer frei bleibt, geht die Reaktion ungestört fort,

- Nickelflaschen beliebiger Form und Gröfse fertigt preiswert aus chemisch reinem Nickel die bekannte Firma Krupp in Berndorf. 
bis das Natrium verbraucht ist. Auf dem Drahtnetz bleiben die nie fehlenden Unreinigkeiten des Natriums zurück, eine schmierige Masse. Deshalb erhält man auf diesem Wege noch reinere Natronlauge, als ob man das Natrium direkt in die Schale tut, in der sich die Lauge sammelt.

Die erbaltene Lauge ist etwa vierzig prozentig und absolut rein. Will man die Vorsicht übertreiben, so kann man dem Sperrwasser des Apparates zum noch vollständigeren Fernhalten des Kohlendioxyds etwas Natronlauge zusetzen. Das Sperrwasser wird in dem Malse, wie es verdunstet, nachgefüllt. Ist das Natrium verbraucht, so reinigt man den Drahtnetztrichter, ehe man ihn neu beschickt. Die in der Flasche angesammelte Natronlauge giefst man bei dieser Gelegenheit in die etwa 21 fassenden Vorratsflaschen aus Reinnickel. Die Gröfsenverhältnisse wird man so wählen, dafs die Lauge aus einer Natriumbeschickung die Auffangeflasche etwa zu $2 / 3$ anfüllt.

Bezüglich der Kosten des so gewonnenen Natriumhydroxyds

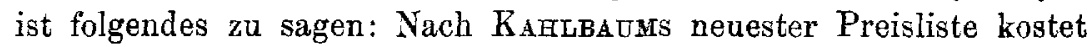
$1 \mathrm{~kg}$ Natrium $4.50 \mathrm{M}$., $1 \mathrm{~kg}$ Natriumhydroxyd aus Natrium 9 M., $1 \mathrm{~kg}$ Natriumbydroxyd mit Alkohol gereinigt $2.60 \mathrm{M}$. Da $1 \mathrm{~kg}$ Natrium $1.74 \mathrm{~kg}$ Natriumhydroxyd liefert, so kostet von letzterem $1 \mathrm{~kg} 2.60 \mathrm{M}$., also genau so viel, wie das käufliche, mit Alkohol gereinigte, das aber in Hinblick darauf, dafs es ja nicht hundertprozentig ist, sogar noch teurer ist, als das selbst aus Natrium gewonnene, absolut reine. Es ist deshalb unbedingt rationeller, sich die Natronlauge selbst aus Natrium herzustellen, als das mit Alkohol gereinigte oder gar das fast viermal teurere, aus Natrium gewonnene Produkt zu kaufen. In meinem Laboratorium wird deshalb seit etwa vier Jahren der ganze Bedarf an reiner Natronlauge für analytische und präparative Zwecke in der geschilderten Weise aus metallischem Natrium hergestellt, und dabei ist der Apparat so leistungsfähig, dafs er zeitweise aufser Betrieb bleiben kann. Ich folge deshalb gern der Aufforderung mehrerer Fachgenossen, welche die Vorrichtung bei mir im Betriebe sahen, die Vorteile derselben durch Veröffentlichung allgemein zugänglich zu machen.

Clausthal, Chem. Institut der Bergakademie, August 1904.

Bei der Redaktion eingegangen am 15. August 1904. 